\title{
Towards a Taxonomy of Impact Factors for Digital Platform Pricing
}

\author{
Virginia Springer ${ }^{(\bowtie)}(1]$ and Dimitri Petrik \\ Department VIII: Information Systems II, University of Stuttgart, Keplerstr. 17, \\ 70174 Stuttgart, Germany \\ springervirginia@googlemail.com, \\ dimitri.petrik@bwi.uni-stuttgart.de
}

\begin{abstract}
Solving the chicken-or-egg problem and leveraging value contributing actors on the platform is crucial to establish dynamic platform-based ecosystems. A digital platform provider is challenged to manage multilateral platform architecture and governance mechanisms to establish an attractive platform-based ecosystem to foster third-party complementors to join. One of the key issues while establishing a platform-based ecosystem remains the decision about an adequate pricing model. Despite a large number of publications on platform governance, detailed pricing model analyses remain rare. In this explorative paper, we conduct a literature review, studying 62 relevant papers to explore the pricing impact factors to create a foundation for future research of price models in the under-researched setting of the Industrial Internet of Things (IIoT). The most relevant pricing factors and their distinctive characteristics are summed up in a multi-dimensional taxonomy. The developed taxonomy includes 13 impact factors and 38 characteristics of platform pricing. Our findings enable the decomposition and understanding of price models for their future improvement.
\end{abstract}

Keywords: Platform pricing $\cdot$ Pricing impact factors $\cdot$ Pricing taxonomy $\cdot$ IIoT platforms $\cdot$ IIoT platform pricing $\cdot$ Literature Review

\section{Introduction}

The Internet of Things (IoT) and its industrial area of application (IIoT) build a toppriority topic in the digitization of products and processes. Digitized products erode the established boundaries between the companies, e.g., by making the customer data available for sharing and processing, ultimately leveraging value-added services $[1,2]$. Industrial companies rely on digital industrial platforms, known as IIoT platforms, since they operate as scalable middleware systems in digital infrastructure, integrating networked subsystems and heterogenous third parties in the value creation process [3, 4]. Besides, platforms offer a stable set of functionalities as an extensible technological foundation for modular innovations to be built upon. Since the services can be co-created by multiple actors, platforms also organize the interaction in an ecosystem, providing a transactional base. Hence, IIoT platforms correspond simultaneously to the innovation and transaction platform concepts $[4,5]$. Similarly, indirect network effects and generativity are recognized positive effects of platformization, requiring an innovation-contributing ecosystem

(C) The Author(s) 2021

P. Gregory and P. Kruchten (Eds.): XP 2021 Workshops, LNBIP 426, pp. 115-124, 2021.

https://doi.org/10.1007/978-3-030-88583-0_11 
of platform users [5]. Following the idea of ecosystem development, it is in the platform providers' interest to shift industrial supply relationships into platform-based transactions and transform the supply chains into ecosystem participants [6]. The operation of digital platforms incurs costs, and apart from the initial development of the platform core, the variable cost of attracting new platform users can be high. This is caused by subsidizing the actors, as one of the known platform launch strategies is to subsidize certain user segments to engage them to join the ecosystem and solve the "chickenegg-dilemma" [7-9]. In the IIoT, attracting new actors is an even bigger challenge due to the different functioning of indirect network effects, the non-standardized business relationships, and the variety of complementary partner types [4, 6]. However, most IIoT platforms on the market charge different platform-ecosystem participation fees, pursuing different pricing strategies [10]. Pricing strategies are understood as strategic approaches that "a firm adopts to determine what it will charge for its products and services [11]". In this context, pricing impact factors combine designable parameters and exogenous characteristics (i.e., platform economics), determining the pricing strategy. Although the platform research agrees on the importance of pricing models in ecosystem development and categorizes pricing as a relevant pillar in software product strategy [12], there are only a few research works $[9,13]$ that offer in-depth analysis of the existing price strategies and impact factors in the context of platform-ecosystems. Inspired by this state of research, our research goal for this preliminary paper is to identify the price impact factors relevant for the pricing strategy of digital platforms by conducting a literature review and discovering suitable price impact factors from the broad research field on digital platforms.

\section{Theoretical Background}

The IoT paradigm integrates technology-enabled physical objects into a global cyberphysical network that changes how to create added value. The concepts of IoT and IIoT are often equated in theory due to their (technological) similarity. However, multiple characteristics differ depending on the end-users, the industry focus, the underlying service models, and the connected things. IIoT supports the emergence of digital and smart manufacturing, aiming to integrate operation technology (OT) and IT domains to create economic value. Therefore, industrial organizations are usually considered the primary end-users. Thus, the IIoT aims to connect all industrial assets, including machines and control systems, intra-organizational information systems (IS), and business processes in a B2B environment $[4,14]$. IIoT platforms can be seen as middleware systems that orchestrate the heterogeneous landscape of connected assets and software systems. Hence, the IIoT platform usually provides a technological infrastructure fostering connectivity and interoperability between intelligent machines, control systems, and software systems $[3,6,14]$. On top of the technological infrastructure, applications enable data-driven services to the platform users. While traditional pipeline companies operate within corporate boundaries, platform providers use an ecosystem of autonomous parties to create shared value and exploit the potentials of generativity [15]. From a technical perspective, platforms offer an extensible technological foundation on top of which third parties can build value-adding applications [13]. From an organizational view, platforms act as multi-sided markets, acting between several user segments to bring them 
together in an overarching ecosystem [16]. Fostering users to join a platform-based ecosystem, platform providers can operate different mechanisms within the architecture and governance fields of action [13]. Pricing is recognized as one of the governance mechanisms and a platform launch strategy since a platform provider can vary the price model between different market sides and subsidize specific user groups [7]. Besides, a platform provider can define the revenue sharing model to foster the complementors' innovation activities [13]. Preliminary work considers multiple connection points between the ecosystem participants and IoT platforms that can be charged for [17]. However, only a few studies offer a holistic overview of the existing platform price impact factors, especially considering the enterprise instantiation of the platform in the IIoT. As Schreieck et al. already mentioned, the price model for IoT platforms may depend on heterogeneous factors determined by the inherent technological complexity [17]. To sum up, the lack of knowledge on the IIoT platform pricing makes a literature review necessary to reduce the complexity in the design of price models regarding their underlying impact factors.

\section{Research Methodology}

We developed a three-stage research framework to guide the development of a pricing taxonomy. Classification plays an important role, structuring knowledge on a particular object of interest. Since many classification approaches lack a profound methodology, we consequently adopted our overall procedure to the widely used iterative taxonomy development approach presented by Nickerson et al. [18]. We opted for Nickersons' approach since it is already evaluated and established in the IS research [19, 20].

According to the taxonomy development procedure, we identified metacharacteristics as well as ending conditions first. Meta-characteristics help to define the purpose of the taxonomy and address the interests of future research. We used the VISOR framework according to [21] to define our meta-characteristics. As already shown in Sect. 2, the characteristics of platform business models differ from traditional business models primarily in terms of the exponential relationship between the value and the number of users of a platform, the value creation in ecosystems, and the ability to interoperate with other services. Since the VISOR framework emphasizes the importance of digital platforms' central role, the need to orchestrate multiple actors in ecosystems, and consider the multitude of interfaces (as customer touchpoints), it seems suitable to align the derived impact factors with the dimensions of the framework. It hence composes digital business models in the five dimensions of Value Proposition, Interface, Service Platforms, Organizing Model, and Revenue Model. In line with Nickerson, the subjective ending conditions aim to ensure comprehensive, extendible, concise, robust, and explanatory results. The ending conditions mainly include specifications on the objects' classification, representativeness of the impact factors, changes in the taxonomy, and the uniqueness of the impact factors and characteristics. Since the purpose of our taxonomy is to provide a representative overview of the pricing impact factors for IIoT platforms in an emerging domain, we followed a conceptual-to-empirical approach.

Following the conceptional-to-empirical approach, we built our initial taxonomy iteratively on existing literature. We screened the titles, abstracts, and - where necessary - full-texts to conduct a rigorous literature analysis, which was summed up in a 
concept matrix. In particular, literature that refers to pricing or merely mentions it but does not examine it was excluded. Our literature analysis mainly focused on economic models on multi-sided markets and empirical or conceptional studies on platform governance investigating pricing impact factors. We used various keyword combinations like "multi-sided platform pricing" or "platform governance pricing" in multiple iterations to build an initial corpus consisting of 45 papers, building the first iteration (conceptualto-empirical). With exclusive forward and backward research (second iteration), the corpus included 62 final papers for analysis, building the third iteration (conceptual-toempirical). The overview of the search details as well as the complete list of papers and a concept matrix are available at the following URL: https://bit.ly/3g4PyG2.

In line with the concept of triangulation, we mainly focused our analysis in the first iteration on economic models on multi-sided markets and identified eight impact factors. Our second iteration that mainly focused on empirical and conceptional studies on platform governance identified three more impact factors. In the third and last iteration, we identified in total 13 pricing impact factors encompassing 38 characteristics. Each dimension is indicated by mutually exclusive (E) or non-exclusive (NE) characteristics.

\section{Taxonomy}

This section presents our taxonomy systematizing the derived price model impact factors with their characteristics, structured according to the VISOR framework's dimensions.

Table 1. Taxonomy of Price Impact factors for Digital Platforms

\begin{tabular}{|c|c|c|c|c|c|c|c|}
\hline Dimension & & Impact factor & & Char: & icteristics & & E/NE \\
\hline & $\mathrm{P} 1$ & Market structure & Monopoly & \begin{tabular}{|l|l} 
Duopoly \\
\end{tabular} & Olis & opoly & $\mathrm{E}$ \\
\hline $\begin{array}{c}\text { Value } \\
\text { Proposition }\end{array}$ & P2 & $\begin{array}{c}\text { Platform } \\
\text { differentiation }\end{array}$ & Platform offer & Network size & Bundling & of services & $\mathrm{NE}$ \\
\hline & P3 & Platform offer & Specializ & ed platform & Platform offers & ndustry solutions & $\mathrm{E}$ \\
\hline & P4 & Platform access & & pen & Res & icted & $\mathrm{E}$ \\
\hline Intertace & P5 & Boundary Resources & ABR & DBR & & BR & $\mathrm{NE}$ \\
\hline & P6 & Modularity & Low $\mathrm{m}$ & odularity & High $n$ & dularity & $\mathrm{E}$ \\
\hline Service & P7 & Platform architecture & \begin{tabular}{|l|} 
Purists \\
\end{tabular} & Analysts & Connectors & Allrounder & $\mathrm{E}$ \\
\hline & P8 & Platform lifecycle & Emerging & Growth & Maturity & Saturation & $\mathrm{E}$ \\
\hline Organizing & P9 & $\begin{array}{c}\text { Information } \\
\text { availability }\end{array}$ & $\operatorname{trans}$ & sparent & Not tr: & ssparent & E \\
\hline Model & P10 & Network effects & $\begin{array}{l}\text { Indirect posi- } \\
\text { tive }\end{array}$ & Indirect negative & Direct positive & Direct negative & $\mathrm{NE}$ \\
\hline & P11 & Pricing model & $\begin{array}{c}\text { Subscription- } \\
\text { based }\end{array}$ & Usage-based & One-tim & -Payment & $\mathrm{NE}$ \\
\hline $\begin{array}{c}\text { Revenue } \\
\text { Model }\end{array}$ & P12 & Subsidization & $\begin{array}{r}\text { Asyn } \\
\text { (subsic }\end{array}$ & $\begin{array}{l}\text { nmetric } \\
\text { dization) }\end{array}$ & $\begin{array}{r}\text { Syn } \\
\text { (no sub }\end{array}$ & $\begin{array}{l}\text { netric } \\
\text { idization) }\end{array}$ & E \\
\hline & P13 & Pie-Splitting & Fix & sliding & rising & No pie-splitting & $\mathrm{E}$ \\
\hline
\end{tabular}

Value Proposition: This dimension contains the three pricing impact factors market structure (P1), platform differentiation (P2), and platform offer (P3). P1 is determined by the supply and demand sides' number and size and describes an economic market's structure and composition. Existing research focuses primarily on the ideal-typical case 
of a monopoly and partly on the case of a duopoly. Only in a few investigations, the oligopoly case has been considered yet. Against this background, existing research shows that monopolies generally have greater freedom to set prices and that pricing options may decrease as competition increases [22, 23]. P2 subsumes those characteristics of an ecosystem that are aimed at the heterogeneity of value creation ecosystems. This non-exclusive impact factor shows how platform providers can differ from one another. We distinguish the three characteristics platform offering, network size, or bundling of services. In this context, recent research shows that the price can significantly depend on the network size $[24,25]$. According to research, product differentiation always leads to higher welfare through better demand stimulation, which directly impacts price [26]. Also, bundling of services can lead to higher demand stimulation and thus significantly influence pricing [27]. Whether combinations of these characteristics (e.g., platform offer and bundling) are correlated and how they influence the price have not been investigated yet. Lastly, P3 distinguishes between platforms that focus on specialization or platforms that offer industry-wide solutions. Against this background, specialization of the platform offering is accompanied by higher demand stimulation for heterogeneous markets since specialized platform providers are less substitutable and can respond better to the specific customer demands [28].

Interface: This dimension contains the impact factors platform access ( $\mathrm{P} 4)$ and boundary resources (BR) (P5). Both are closely related to providing services and access to the underlying platform. The platform access may vary between openness and restrictions set by the platform provider. Against this background, platform openness can significantly influence the platform's attractiveness, directly impacting the price [29, 30]. P5 indicates that payment barriers for the use of specific BRs may be set up [17]. BRs represent different technical and non-technical resources for third-party access of the platform that can be conceptually divided into application BR (ABR), development (BR), and social BR (SBR) [31]. For instance, a platform provider can charge additional fees for participation in the partner program or support.

Service Platform: This dimension describes the impact factors modularity (P6), platform architecture (P7), and platform lifecycle (P8) that enable, shape, and support the business processes and relationships in platform ecosystems. P6 subsumes characteristics related to the platform modularity since they are hardly reversible later and, therefore, influence orchestration and aligning price level [13]. P7 describes how the architecture of platforms may differ, affecting the price due to the different levels of modularity and the added value (i.e., generic development tools or specific use case analyses). For instance, using an IoT platform may result in full-stack services or solely in high-end analytics, which requires distinctive pricing [32]. Lastly, $\mathbf{P 8}$ subsumes those characteristics related to the degree of performance or the degree of exploitation of competitive potential by the platform. Against this background, it is crucial to consider how technologies and technological concepts such as digital platforms reach technical performance limits in their further development potential [13]. Depending on the growth ambition of the platform provider in different phases, subsidization may influence the price.

Organizing Model: This dimension addresses the fundamental organizational model of digital platforms and describes how business processes, value chains, competition, 
and partner relationships need to be organized. We distinguish the two pricing impact factors, information availability (P9) and network effects (P10). The P9 subsumes those characteristics that relate to information transparency in the platform ecosystem. Information transparency is crucial for a perfect market and is given when all actors in the ecosystem possess all information about environmental states and their actions. This also includes information about the uncertainty that can arise in a transaction (on a digital platform). The platform operator's influence is indirect since the entire ecosystem determines information availability and related uncertainties. Existing results show that information transparency and the associated uncertainties directly impact price elasticity [33]. According to [34], transparent (price) information leads to users' expectations being better met and thus to the effect of price reductions being strengthened. P10 summarizes the interdependent relationships between the various actors that determine platform business models' success in ecosystems. The four characteristics, including indirect positive, indirect negative, direct positive, and direct negative, can be distinguished based on the literature analysis. Established research shows that the platform operator's optimal prices depend on how (new) participants influence the attractiveness of the ecosystem [35]. Moreover, pricing should also take into account how strongly participants in the ecosystem respond to network effects in general [36].

Revenue Model: This dimension includes the three impact factors: pricing model (P11), subsidization (P12), and pie-splitting (P13). P11 subsumes non-exclusive fees that may be incurred by ecosystem actors when using the platform. These are usually linked to licensing and are either subscription-based, usage-based pricing models or a one-time payment. P12 indicates whether the platform access fees hit all sides of a platform or whether specific sides are subsidized. Accordingly, one can distinguish between symmetric (no subsidization) and asymmetric (subsidizing a market side) revenue models. According to [37], a subsidization interest for platform providers results from indirect network effects. Against this background, [26] show that the side that is more price-sensitive should be subsidized. Consequently, revenues for the platform operator are primarily generated on that side of the market that is more affected by network effects. Therefore, this market side contributes to increased market participation [38]. Lastly, P13 relates to revenue sharing and associated pie-splitting conditions between the platform provider and the platform users. Typically, complementors can be charged for selling their platform-based solutions. Four types of pie splitting were already recognized: fixed, sliding, rising, and no pie-splitting [13]. Sliding refers to a decreasing revenue share with increasing demand while rising forces an increasing revenue share with increasing demand. Existing research by Rochet and Tirole shows that rising piesplitting conditions, in particular, are an effective means of increasing the attractiveness of a platform for homogeneous products or services [16]. Although pie-splitting conditions can directly contribute to ecosystem development, especially in the platform life cycle's early phases, blueprints for adequate pie-splitting models for heterogeneous platform domains, such as IIoT, have not yet been considered in the literature. 


\section{Discussion and Conclusion}

This paper used a structured literature review to derive a multidimensional taxonomy of price model impact factors for digital platforms. Our findings have implications for the following three research discourses. Firstly, they contribute to clarifying possible pricing impact factors by enabling a more differentiated understanding of pricing impact factors at various levels of platform business models. Thus, our preliminary work responds to current demands for more transparency and further research in this emerging area and provides a grounding for domain-specific pricing research in the IIoT context. Secondly, the derived impact factors move forward the research on the platform governance and platform establishment strategies $[7,17]$ since the taxonomy creates transparency for the pricing design and enables platform providers to adjust the prices more delicately. Consequently, the price level for accessing the platform can be adjusted according to the participation level differing between the ecosystem participants and supporting stakeholderspecific platform governance [10]. Besides, our findings may support implementing the so-called "goldilocks" rule considering the platform price level [13]. Thirdly, most of the impact factors were extracted from the literature on multi-sided markets, being studied less from the platform governance research stream. Accordingly, the results build one of the early contributions to transfer the findings from the economic research field to the platform governance stream within the platform research [39] since the platform governance literature primarily classifies pricing as a governance mechanism without going into much detail [17].

From a practical perspective, the taxonomy provides a foundation for pricing decisions and may support platform providers in the creation of a price strategy blueprint. However, regardless of the results obtained, we have to point out the current limitations of the taxonomy. The current state of the taxonomy lacks empirical validation with marketready IoT platform providers. Therefore, additional empirical-to-conceptual validation of the taxonomy is lacking. Consequently, the taxonomy also does not offer domainspecific archetypes of pricing strategies for IoT platforms. Since there has been little research to date on pricing impact factors in the context of IIoT platforms, it is conceivable that the impact factors and characteristics selected for the taxonomy will apply only conditionally to (future) IIoT platforms. Motivated by these limitations, our future research will focus on empirical validation of the taxonomy, with a subsequent clustering to identify pricing strategies for IIoT platforms. Besides, with the addition of empirical studies, it is to be expected that the taxonomy may need to be adapted, as the IIoT market itself is very dynamic, and so are the associated business models. Therefore, it is likely that as new IIoT platform business models evolve, there may be new pricing impact factors and that impact factors that are currently possibly underrepresented will gain importance and relevance. Therefore, it is necessary to regularly update the taxonomy and extend it accordingly to ensure representative results. Due to this, the taxonomy represents only a first step towards structuring possible pricing impact factors in the context of the IIoT and reveals significant deficits that offer further research opportunities. Besides, the analysis of the existing price impact factors forms the basis for composing a research agenda on platform pricing in the context of platform ecosystems. 


\section{References}

1. Porter, M., E., Heppelmann, J. E.: How smart connected products are transforming competition. Harvard Bus. Rev. 92(11), 64-8 (2014)

2. Leminen, S., Rajahonka, M., Wendelin, R., Westerlund, M.: Industrial internet of things business models in the machine-to-machine context. Ind. Mark. Manage. 84, 298-311 (2020)

3. Mineraud, J., Mazhelis, O., Su, X., Tarkoma, S.: A gap analysis of Internet-of-Things platforms. Comput. Commun. 89-90, 5-16 (2016)

4. Pauli, T., Fielt, E., Matzner, M.: Digital industrial platforms. Bus. Inf. Syst. Eng. 63(2), 181-190 (2021). https://doi.org/10.1007/s12599-020-00681-w

5. Gawer, A.: Digital platforms' boundaries: the interplay of firm scope, platform sides, and digital interfaces. Long Range Planning (appearing soon)

6. Petrik, D., Herzwurm, G.: Towards the IIoT ecosystem development - understanding the stakeholder perspective. In: Proceedings of the 28th ECIS, pp. 1-17, Marrakesh, Morocco (2020)

7. Stummer, C., Kundisch, D., Decker, R.: Platform launch strategies. Bus. Inf. Syst. Eng. 60(2), 167-173 (2018). https://doi.org/10.1007/s12599-018-0520-x

8. Kenney, M., Rouvinen, P., Seppälä, T., Zysman, J.: Platforms and industrial change. Ind. Innov. 26(8), 871-879 (2019)

9. Cusumano, M.A., Gawer, A., Yoffie, D.B.: The Business of Platforms: Strategy in the Age of Digital Competition, Innovation, and Power. HarperBusiness, New York (2019)

10. Wareham, J., Fox, P.B., Cano Giner, J.L.: Technology ecosystem governance. Organ. Sci. 25(4), 1195-1215 (2014)

11. Sammut-Bonnici, T., Channon, D.F.: Pricing Strategy. Wiley Encyclopedia of Management, New York (2015)

12. Kittlaus, H.-B., Clough, B.: Software Product Management and Pricing. Springer, BerlinHeidelberg (2009)

13. Tiwana, A.: Platform Ecosystems: Aligning Architecture, Governance, and Strategy. Mor-gan Kaufmann, Amsterdam (2014)

14. Wortmann, F., Flüchter, K.: Internet of things. Bus. Inf. Syst. Eng. 57(3), 221-224 (2015). https://doi.org/10.1007/s12599-015-0383-3

15. Hein, A., Weking, J., Schreieck, M., Wiesche, M., Böhm, M., Krcmar, H.: Value co-creation practices in business-to-business platform ecosystems. Electron. Mark. 29(3), 503-518 (2019). https://doi.org/10.1007/s12525-019-00337-y

16. Rochet, J.-C., Tirole, J.: Platform competition in two-sided markets. J. Eur. Econ. Assoc. 1(4), 990-1029 (2003)

17. Schreieck, M., Hakes, C., Wiesche, M., Krcmar, H.: Governing platforms in the internet of things. In: Ojala, A., Holmström Olsson, H., Werder, K. (eds.) ICSOB 2017. LNBIP, vol. 304, pp. 32-46. Springer, Cham (2017). https://doi.org/10.1007/978-3-319-69191-6_3

18. Nickerson, R.C., Varshney, U., Muntermann, J.: A method for taxonomy development and its application in information systems. Eur. J. Inf. Syst. 22(3), 1-24 (2013)

19. Lösser, B., Oberländer, A. M., Rau, D.: Taxonomy research in information systems: a systematic assessment. In: Proceedings of e $27^{\text {th }}$ ECIS, pp. 1-17, Stockholm-Uppsala, Schweden (2019).

20. Omair, B., Alturki, A.: An improved method for taxonomy development in information systems. Int. J. Adv. Comput. Sci. Appl. 11(4), 535-540 (2020)

21. El Sawy, O.A., Pereira, F.: VISOR: a unified framework for business modeling in the evolving digital space. In: Werder, K. (ed.) Business Modelling in the Dynamic Digital Space. SDS, pp. 21-35. Springer, Heidelberg (2013). https://doi.org/10.1007/978-3-642-31765-1_3 
22. Hagiu, A., Jullien, B.: Why do intermediaries divert search? Rand J. Econ. 42(2), 337-362 (2011)

23. Godes, D., Ofek, E., Sarvary, M.:. Content vs. advertising: the impact of competition on media firm strategy. Market. Sci. 28(1), 20-35 (2009).

24. Cabral, L.: Towards a theory of platform dynamics. J. Econ. Manag. Strategy 28(1), 60-72 (2019)

25. Guijarro, L., Vidal, J.R., Pla, V., Naldi, M.: Economic analysis of a multi-sided platform for sensor-based services in the internet of things. Sensors 19(2), 373 (2019)

26. Chakravorti, S., Roson, R.: Platform competition in two-sided markets: the case of payment networks. Rev. Netw. Econ. 5(1), 118-142 (2006)

27. Amelio, A., Jullien, B.: Tying and freebies in two-sided markets. Int. J. Ind. Organ. 30(5), 436-446 (2012)

28. Hagiu, A.: Two-sided platforms: product variety and pricing structures. J. Econ. Manag. Strategy 18(4), 1011-1043 (2009)

29. Tan, G., Zhou, J.: The effects of competition and entry in multi-sided markets. Rev. Econ. Stud. 88, 1002-1030 (2021)

30. Schreieck, M., Hein, A., Wiesche, M., Krcmar, H.: The challenge of governing digital platform ecosystems. Digital marketplaces unleashed, 527-538 (2018).

31. Dal Bianco, V., Myllärniemi, V., Komssi, M., Raatikainen, M.: The role of platform boundary resources in software ecosystems: a case study. In: 2014 IEEE/IFIP Conference on Software Architecture, pp. 11-20, Sydney, Australia (2014).

32. Arnold, L., Jöhnk, J., Vogt, F., Urbach, N.: A taxonomy of industrial IoT platforms' architectural features. In: Proceedings of 16th International Conference on Wirtschaftsinformatik, Essen, Germany (2021)

33. Jullien, B., Pavan, A.: Information management and pricing in platform markets. Rev. Econ. Stud. 86(4), 1666-1703 (2019)

34. Hagiu, A., Hałaburda, H.: Information and two-sided platform profits. Int. J. Ind. Organ. 34, 25-35 (2014)

35. Evans, D.S.: Some empirical aspects of multi-sided platform industries. Rev. Netw. Econ. 2(3), 191-209 (2003)

36. Gabszewicz, J.J., Laussel, D., Sonnac, N.: Does advertising lower the price of newspapers to consumers? A theoretical appraisal. Econ. Lett. 87(1), 127-134 (2005)

37. Caillaud, B., Jullien, B.: Chicken \& egg: competition among intermediation service providers. RAND J. Econ. 309-328 (2003)

38. Bolt, W., Tieman, A.F.: Heavily skewed pricing in two-sided markets. Int. J. Ind. Organ. 26(5), 1250-1255 (2008)

39. Schüler, F., Petrik, D.: Objectives of platform research: a co-citation and systematic literature review analysis. In: Seiter, M., Grünert, L., Steur, A. (eds.) Management Digitaler Plattformen. Z, vol. 75/20, pp. 1-33. Springer, Wiesbaden (2021). https://doi.org/10.1007/978-3-658-311 $18-6 \_1$ 
Open Access This chapter is licensed under the terms of the Creative Commons Attribution 4.0 International License (http://creativecommons.org/licenses/by/4.0/), which permits use, sharing, adaptation, distribution and reproduction in any medium or format, as long as you give appropriate credit to the original author(s) and the source, provide a link to the Creative Commons license and indicate if changes were made.

The images or other third party material in this chapter are included in the chapter's Creative Commons license, unless indicated otherwise in a credit line to the material. If material is not included in the chapter's Creative Commons license and your intended use is not permitted by statutory regulation or exceeds the permitted use, you will need to obtain permission directly from the copyright holder.

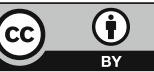

